\title{
Tecnologias móveis na educação: reflexões e práticas
}

Thamiris Oliveira de Araujo ${ }^{1}$

\begin{abstract}
Resumo
O objetivo deste artigo é lançar luz às potencialidades dos dispositivos móveis no âmbito educacional, tecendo reflexões sobre a expansão da tecnologia móvel e a sua integração à aprendizagem. 0 estudo demonstra através de dados dos relatórios da International Telecommunication Union de 2017 e 2018 que a tecnologia móvel está em ascensão no Brasil e no mundo, o que evidencia o campo propício que é a aprendizagem móvel. Além disso, a partir de teorizações sobre a aprendizagem móvel (MOURA, 2010; TRAXLER, 2009; PEGRUM, 2014; SHARPLE, 2009), busca-se estabelecer definições e parâmetros basilares para este campo educacional emergente. Por último, são apresentadas algumas possibilidades de implementação da aprendizagem móvel na educação básica através do uso de aplicativos enquanto ferramentas cognitivas (JONASSEN et al., 1998). Os aplicativos selecionados foram Kahoot e Youtube, ambos gratuitos e de boa usabilidade, respectivamente, para 0 desenvolvimento de jogos e 0 armazenamento/compartilhamento de vídeos, e colocam-se como um meio para que 0 aluno assuma o papel de designer e curador da aprendizagem.
\end{abstract}

Palavras-chave: Aprendizagem móvel. Educação básica. Aplicativos.

\section{Abstract}

The purpose of this article is to shed light on the potential of mobile devices for education, reflecting on the expansion of mobile technology and the integration of this technology with learning. The study demonstrates through data from the 2017 and 2018 reports of the International Telecommunication Union that mobile technology is on the rise in Brazil and worldwide, which highlights the propitious field that is mobile learning. Besides, based on theories about mobile learning (MOURA, 2010; TRAXLER, 2009; PEGRUM, 2014; SHARPLE, 2009), we seek to establish basic definitions and parameters for this emerging educational field. Finally, some possibilities for implementing mobile learning in basic education through the use of applications as cognitive tools are presented (JONASSEN et al., 1998). The selected applications were Kahoot and Youtubue, which are free and of good usability, respectively, to develop games and to store/share vídeos, enabling the learner to take the role of designer and curator in the learning process.

Keywords: Mobile learning. Basic education. Apps.

\section{Introdução}

O veloz desenvolvimento das tecnologias móveis neste início de século intensificou a comunicação e o compartilhamento de informações na sociedade contemporânea. Dispositivos e redes móveis permitem que o acesso dos indivíduos à internet seja contínuo, gerando uma conexão pervasiva e planetária. Dessa forma, a expansão da tecnologia móvel caracteriza o atual estágio da cibercultura como uma cultura da mobilidade.

\footnotetext{
${ }^{1}$ Doutoranda em Linguística Aplicada. Instituto Federal de Educação, Ciência e Tecnologia Fluminense - Campus Maricá. E-mail: thamiris.araujo@iff.edu.br.
} 
Castell et al. (2004, p. 3) investigam os usos sociais das tecnologias de comunicação sem fio e apontam quatro temas em que se pode evidenciar o impacto das tecnologias móveis na cultura. São eles: (i) a profunda conexão entre a comunicação sem fio e o surgimento de uma cultura jovem móvel; (ii) o processo de transformação da linguagem por mensagens de texto e multimodalidade; (iii) a crescente importância da comunicação sem fio nos processos de mobilização sociopolítica, especialmente fora da política formal; e (iv) as mudanças na prática de tempo e espaço resultantes da comunicação sem fio.

Os temas supracitados contribuem em larga escala na mudança de paradigma sobre 0 conceito de aprendizagem, uma vez que as tecnologias móveis conferem ubiquidade ao acesso à informação e à aquisição de conhecimento. Além disso, assim como Castell et al. (2004), vários estudos têm associado a figura do jovem às tecnologias digitais, tanto no que tange ao uso contínuo e intenso das mesmas, o que indica novas formas de aprender (PRENSKY, 2001; TAPSCOTT, 1999; VEEN; VRAKKING, 2009), quanto à apropriação desta tecnologia para expressão de identidades juvenis (ARTOPOULOS, 2011). A aproximação da geração de estudantes às tecnologias móveis pode indicar a existência de uma familiaridade com o espaço online e as configurações dos dispositivos eletrônicos, que seja profícua para a educação.

Tendo em vista o desenvolvimento educacional que tangencia às tecnologias digitais, o objetivo deste artigo é lançar luz às potencialidades dos dispositivos móveis para a educação, tecendo reflexões sobre a expansão da tecnologia móvel e a sua integração à aprendizagem. Para tal, dados estatísticos com base nos relatórios da International Telecommunication Union de 2017 e 2018 são detalhados, de forma a fundamentar a opção pela abordagem da aprendizagem móvel. Em seguida, conceitos norteadores do campo da aprendizagem móvel (MOURA, 2010; TRAXLER, 2009; PEGRUM, 2014; SHARPLE, 2009) são delineados. Por último, alguns aplicativos gratuitos e de boa usabilidade são apresentados como ferramentas cognitivas para aprender (JONASSEN, 1996). Os aplicativos selecionados são Kahoot e Youtube. Pretende-se destacar as funcionalidades dos aplicativos para a educação básica com ênfase na construção ativa e colaborativa de conhecimento. 
2 Tecnologias móveis no Brasil e no mundo

A International Telecommunication Union (ITU) vem demonstrando que o desenvolvimento tecnológico das tecnologias móveis tem sido tão exponencial quanto 0 crescimento do número de assinaturas de telefones celulares no mundo. O relatório da ITU, publicado em 2018, aponta uma crescente predominância de serviços móveis sobre serviços fixos. 0 número de assinaturas de telefone fixo atingiu o pico em 2006 de 19.2 assinaturas a cada 100 habitantes no mundo, mas nos anos seguintes a aderência a este meio de comunicação foi decrescendo, levando a uma taxa de penetração de $12.4 \%$ de assinaturas em 2018. Em contrapartida, hoje há mais assinaturas de telefone celular do que pessoas no planeta, pois alguns usuários possuem mais de uma assinatura por questões pessoais ou profissionais. 0 relatório revela também que o número de assinaturas por 100 habitantes aumentou de 33.9 em 2005 para 76.6 em 2010, 98.2 em 2015 e uma estimativa de 107 em 2018. Baseando-se em pesquisas domiciliares, o relatório calcula que atualmente $76.4 \%$ da população mundial possui um celular.

As assinaturas ativas de banda larga móvel cresceram rapidamente, de 4.0 assinaturas por 100 habitantes em 2007 para uma estimativa de 69.3\% de assinaturas em 2018. Apresentando um crescimento mais moderado, a taxa de penetração das assinaturas de Internet fixa de banda larga passou de $3.4 \%$ em 2005 para $14.1 \%$ em 2018 . A ITU explica que a predominância de assinaturas de redes móveis sobre redes fixas de banda larga ocorre devido ao fato de as redes móveis serem oferecidas com uma disponibilidade geográfica mais ampla e financeiramente mais acessível na maioria dos mercados nacionais. 0 relatório estima que hoje $51.2 \%$ da população mundial tem acesso à Internet. 0 gráfico abaixo, extraído do relatório da ITU (2018), apresenta a evolução histórica no acesso a assinaturas de telefone celular, indivíduos usando a Internet, assinaturas de telefone fixo, assinaturas de Internet móvel e assinaturas de Internet fixa de banda larga, respectivamente. 


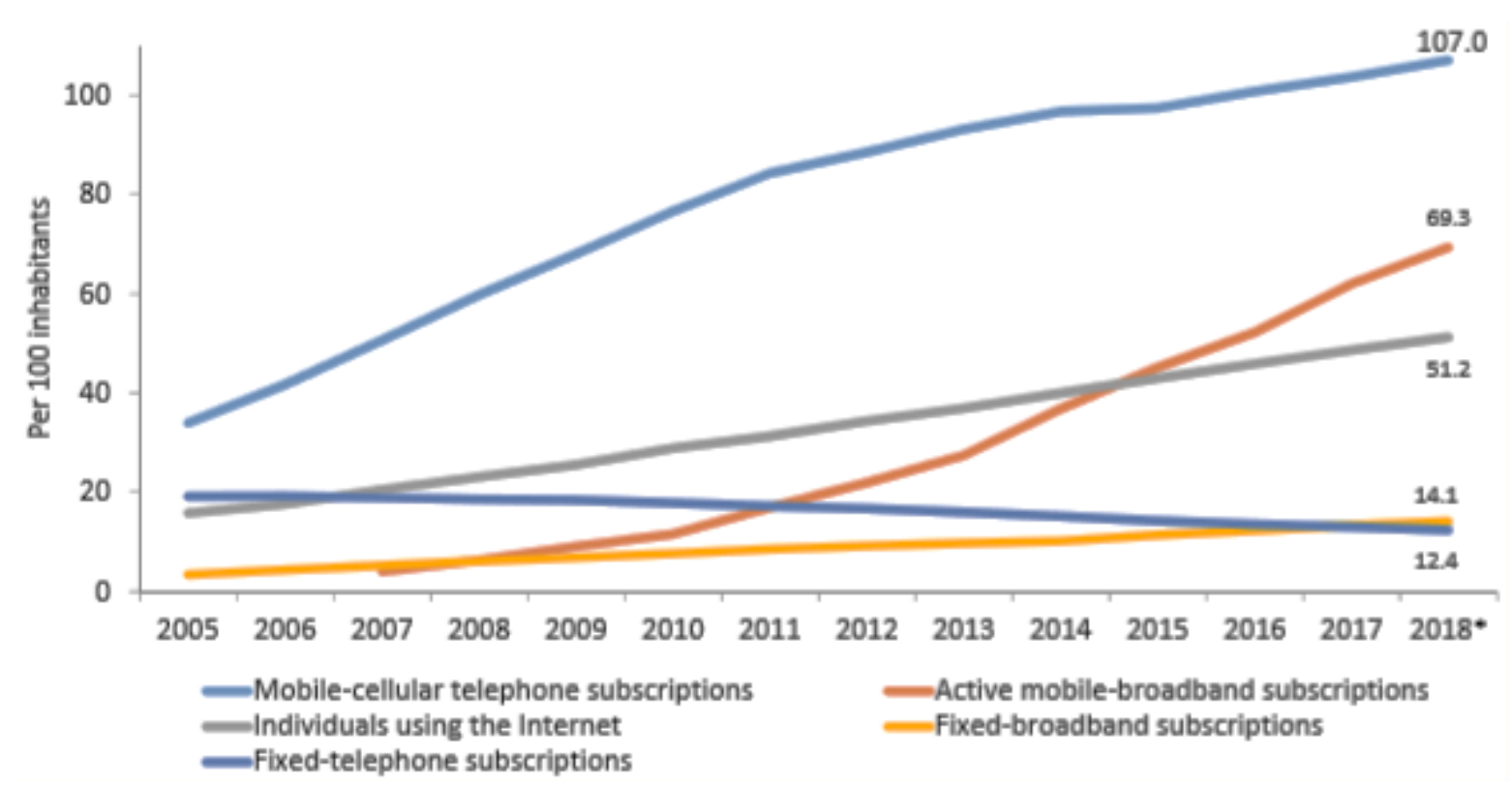

Gráfico 1: Desenvolvimento global das tecnologias de informação e comunicação, 2005-2018*. Nota: *Estimativa da ITU Fonte: ITU (2018).

Uma análise dos relatórios da ITU divulgados em 2017 e 2018 sobre o Brasil informa que o número de assinaturas de telefonia fixa e móvel decresceram sutilmente entre 2016 e 2017, mas, no que tange à telefonia móvel, o número de assinaturas de telefones celulares já ultrapassa o número de habitantes no país. Por outro lado, o acesso à Internet mantém um crescimento gradativo anual. As assinaturas de Internet fixa de banda larga e de Internet móvel cresceram 0.7\% entre 2016 e 2017. O relatório estima que em $201767.5 \%$ dos brasileiros já usavam a Internet, enquanto $60.8 \%$ das residências possuíam acesso à Internet. Tais dados, detalhados nas tabelas 1 e 2, ratificam que a expansão da telefonia e internet móvel no Brasil acompanham os dados de escala mundial ao demonstrar um predomínio de serviços móveis sobre serviços fixos.

\begin{tabular}{|c|c|c|c|}
\hline \multicolumn{2}{|l|}{$\begin{array}{l}\text { Assinaturas de telefone fixo por } \\
100 \text { habitantes }\end{array}$} & $\begin{array}{l}\text { Assinaturas de telefone celular } \\
\text { por } 100 \text { habitantes }\end{array}$ \\
\hline 2016 & 2017 & 2016 & 2017 \\
\hline $20.4 \%$ & $19.5 \%$ & $118.9 \%$ & $113 \%$ \\
\hline
\end{tabular}

Tabela 1. Dados sobre o uso de telefonia no Brasil.

Fonte: Adaptado de ITU (2017 e 2018).

LínguaTec, Instituto Federal de Educação, Ciência e Tecnologia do Rio Grande do Sul, Bento Gonçalves v. 5, n. 1, p. 59-80, jun. 2020. 


\begin{tabular}{|c|c|c|c|c|c|c|c|}
\hline \multicolumn{2}{|l|}{$\begin{array}{l}\text { Percentual de } \\
\text { indivíduos usando a } \\
\text { Internet }\end{array}$} & \multicolumn{2}{l|}{$\begin{array}{l}\text { Percentual de casas } \\
\text { com acesso à } \\
\text { Internet }\end{array}$} & $\begin{array}{l}\text { Assinaturas de } \\
\text { Internet fixa por 100 } \\
\text { habitantes }\end{array}$ & $\begin{array}{l}\text { Assinaturas ativas de } \\
\text { Internet móvel por } \\
100 \text { habitantes }\end{array}$ \\
\hline 2016 & 2017 & 2016 & 2017 & 2016 & 2017 & 2016 & 2017 \\
\hline $59.7 \%$ & $67.5 \%$ & $52.4 \%$ & $60.8 \%$ & $13.0 \%$ & $13.7 \%$ & $89.5 \%$ & $90.2 \%$ \\
\hline
\end{tabular}

Tabela 2. Dados sobre o uso de Internet no Brasil. Fonte: Adaptado de ITU (2017 e 2018).

Apesar de o crescimento de telefonia e Internet móvel estarem em expansão em todo o mundo, uma lacuna entre o acesso e uso das tecnologias de informação e comunicação por países desenvolvidos, em desenvolvimento e menos desenvolvidos permanece evidente. $A$ Organização para a Cooperação e Desenvolvimento Econômico (OCDE) (2001) define o termo fosso digital, em inglês digital divide, como a divisão entre indivíduos, famílias, empresas e áreas geográficas em diferentes níveis socioeconômicos no que diz respeito às suas oportunidades de acesso às Tecnologias de Informação e Comunicação (TICs). $O$ relatório da ITU (2018) informa que os países desenvolvidos têm uma vantagem significativa sobre os países em desenvolvimento nas assinaturas de celular e aproximadamente o dobro do percentual de assinaturas ativas de banda larga móvel e usuários de Internet que os países em desenvolvimento. Os países menos desenvolvidos ficam atrás dos países em desenvolvimento em geral por margens semelhantes. 0 gráfico 2 e 0 gráfico 3 apresentados abaixo demonstram essa associação entre o status de desenvolvimento e o acesso e uso de TICs. 


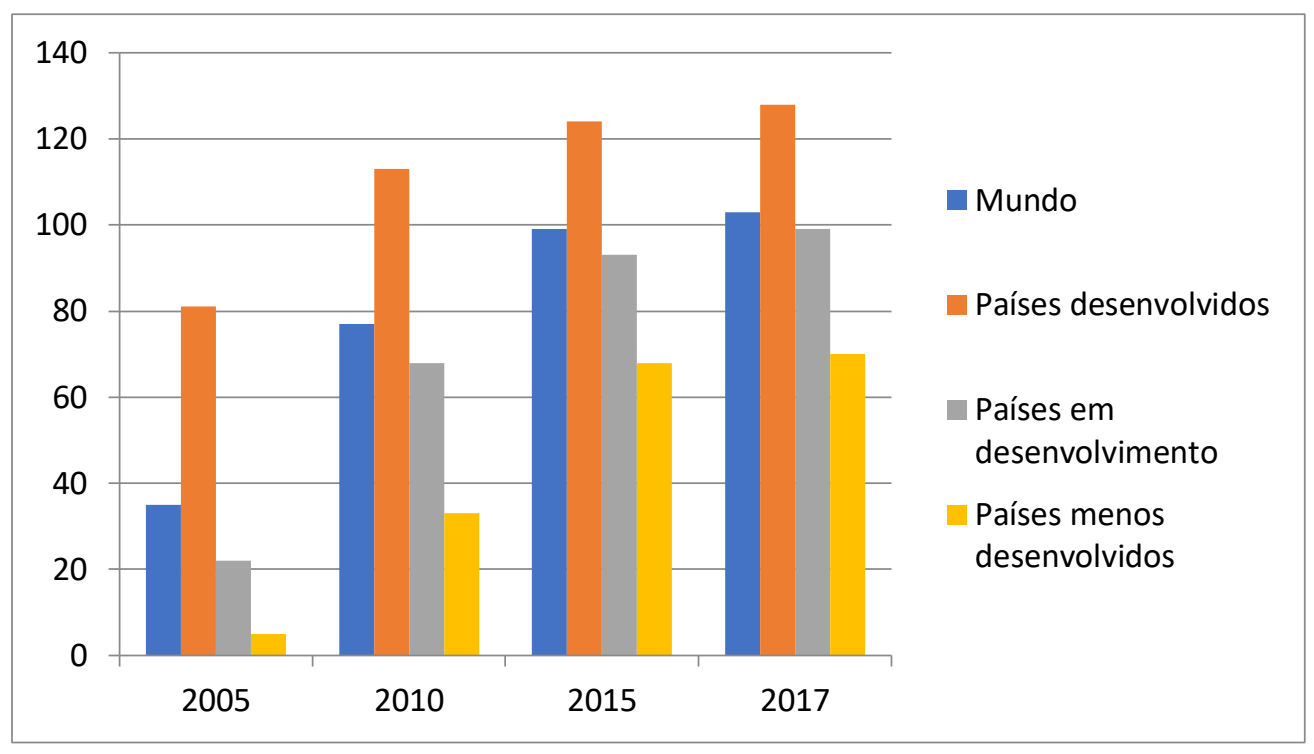

Gráfico 2. Dados sobre o percentual de assinaturas de telefone celular. Fonte: Adaptado de ITU (2018).

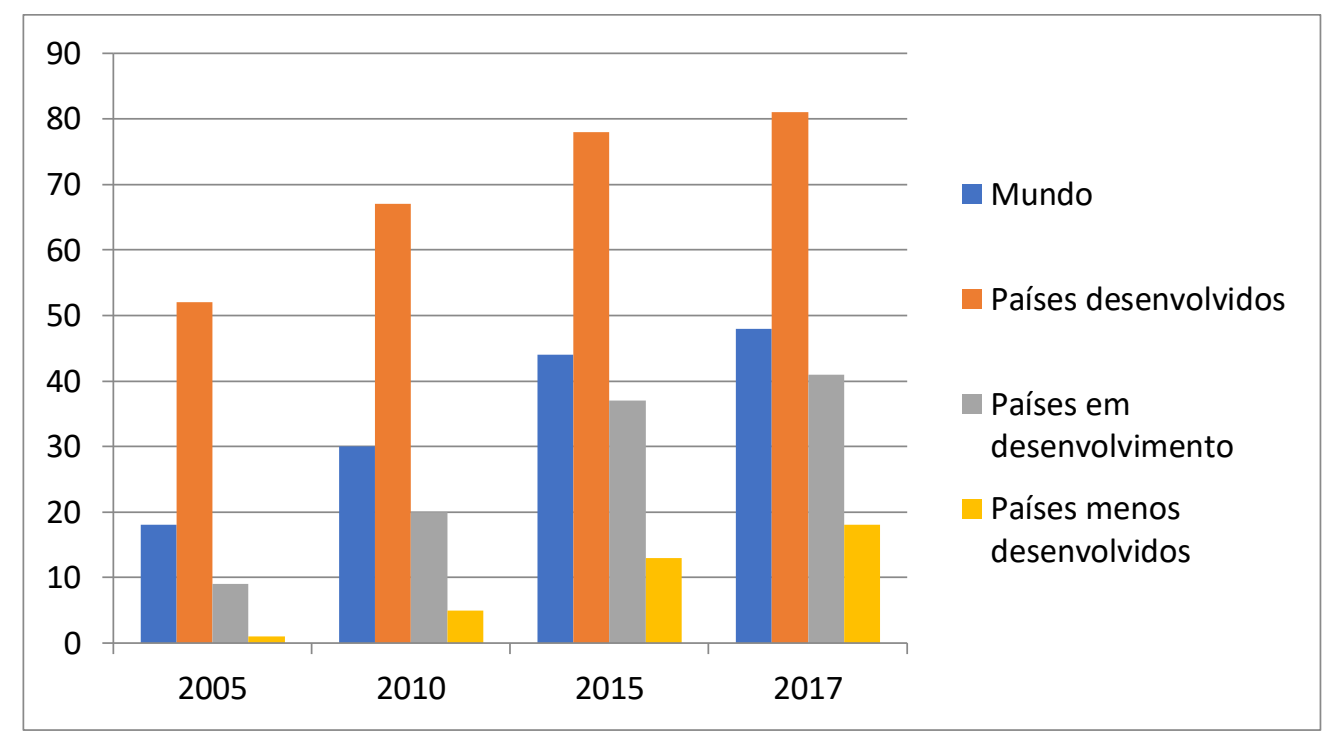

Gráfico 3. Dados sobre o percentual de assinaturas ativas de Internet móvel. Fonte: Adaptado de ITU (2018).

Outro dado revelador sobre o fosso digital explicitado no relatório da ITU de 2017 é a desigualdade entre o acesso e uso da Internet e outras TICs entre homens e mulheres no mundo. A proporção de homens que usam a Internet ainda é maior do que a proporção de mulheres que o fazem em dois terços dos países do mundo. Os dados percentuais de acesso à Internet para homens e mulheres são ilustrados no Gráfico 4. 


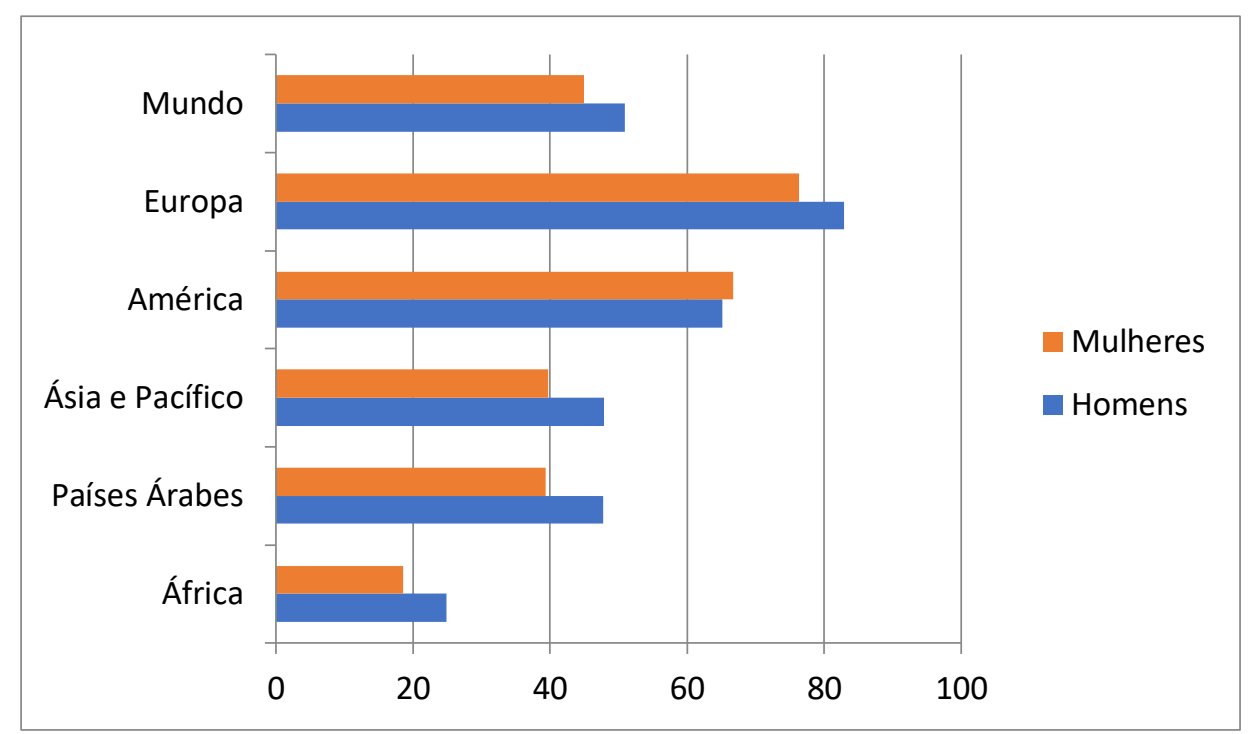

Gráfico 4. Dados sobre o percentual de homens e mulheres utilizando a Internet em 2017 * Nota: *Estimativa da ITU.

Fonte: Adaptado de ITU (2017).

Há também diferenças no uso das TICs entre faixas etárias. Indivíduos jovens, particularmente aqueles entre 15-24 anos de idade, estão mais envolvidos com a Internet. Dados do relatório da ITU de 2017, indicados no Gráfico 5, demonstram que a proporção de pessoas nessa faixa etária que utilizam a Internet, $70.6 \%$ em todo o mundo, é muito maior do que a proporção da população total que está online (48\%). Esses números coadunam com a hipótese levantada por Artopoulos (2011) sobre o surgimento de uma cultura móvel juvenil como uma forma de expressão e reafirmação das identidades dos jovens. No entanto, o autor ressalta que não se limita a identificar a comunicação móvel como "um simples canal, mas, sim, como o dispositivo móvel, com suas funções de comunicação, que se integra à identidade dos jovens e aos processos sociais que the dão sentido". (ARTOPOULOS, 2011, p. 36). 


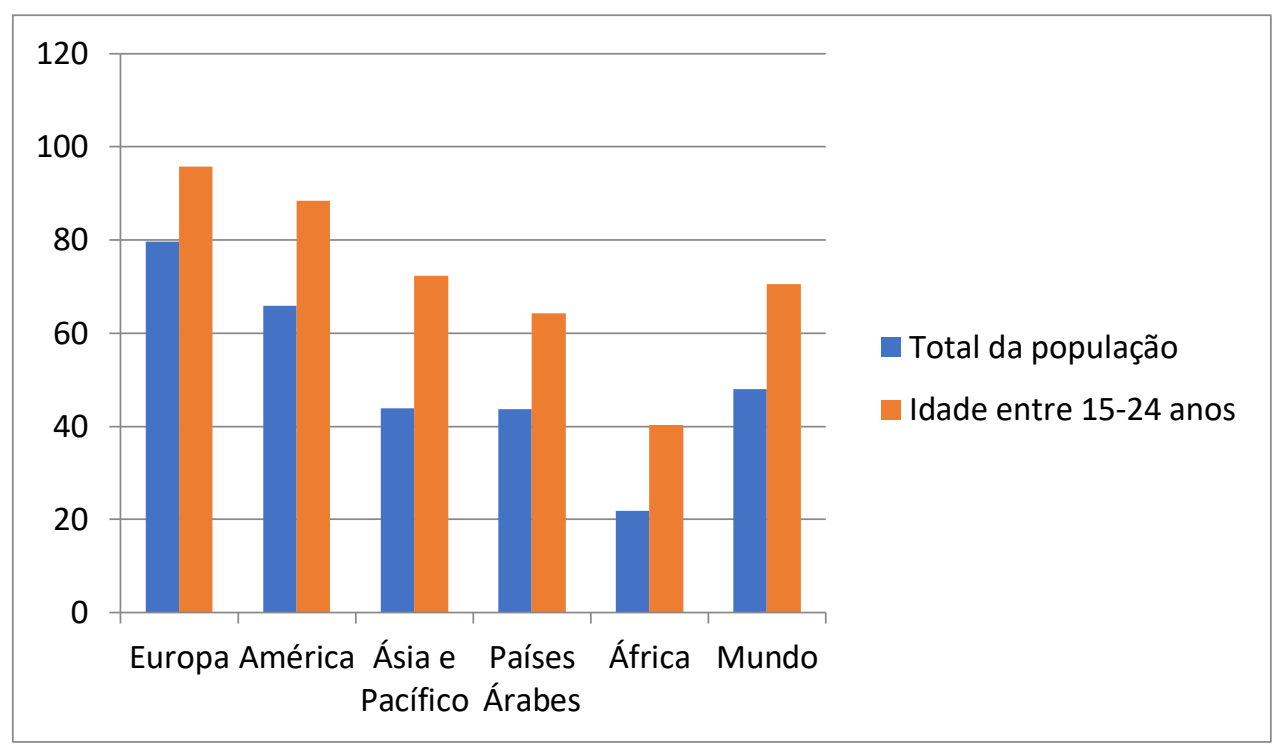

Gráfico 5. Dados sobre o percentual de jovens utilizando a Internet em 2017*. Nota: *Estimativa da ITU.

Fonte: Adaptado de ITU (2017).

Os dados aqui apresentados demonstram a popularização do telefone celular e 0 status do mesmo como meio de acesso à Internet no Brasil e no mundo. É curioso que, embora ainda seja chamado de telefone, a abrangência de funcionalidades dos smartphones coloca em xeque se o seu uso mais importante continua sendo o de transmitir chamadas de voz sem fio. A centralidade que as tecnologias móveis ocupam no cenário contemporâneo estão gestando novas práticas culturais e educacionais. Na próxima seção, serão apresentados conceitos acerca de uma prática educacional emergente: a aprendizagem móvel.

\subsection{Aprendizagem móvel: conceitos}

A aprendizagem móvel ou mobile learning é uma pedagogia moderna que busca integrar os benefícios da cultura da mobilidade para impulsionar avanços na educação. Mobile learning envolve o uso de dispositivos móveis _ como tablets, telefones celulares, aparelhos de $\mathrm{MP}_{3}$ e MP4, dentre outros _ em contextos educacionais, “tendo como característica fundamental a portabilidade dos dispositivos e a mobilidade dos sujeitos, que podem estar física e geograficamente distantes uns dos outros ou em espaços físicos formais de educação, como a sala de aula" (MOURA, 2010, p. 3). 
Moura (2010) ressalta que a aplicação de programas educacionais com dispositivos móveis teve início a partir de 2000 em países europeus e nos Estados Unidos. Desde então, a aprendizagem móvel se desenvolveu enquanto campo de estudo, tornando-se enfoque de conferências acadêmicas internacionais, como a Mobile Learning Week, promovida anualmente pela UNESCO${ }^{2}$, e de periódicos científicos, como o International Journal of Mobile Learning and Organisation ${ }^{3}$ e o International Journal of Interactive Mobile Technologies 4 . A aprendizagem móvel, enquanto linha de pesquisa, abarca teorizações, estudos de caso e experiências obtidas ao desenvolver e aplicar elementos de tecnologias móveis interativas para fins educacionais.

A aprendizagem móvel tem influenciado também o desenho de políticas públicas. Evangelista (2017) comenta que, já em 2005, no Brasil, o governo federal se associou ao projeto americano One Laptop per Child e adquiriu laptops de baixo custo para serem distribuídos a estudantes da rede pública. Outras políticas públicas financiadas pelo governo federal que se destacam nesse âmbito são o Programa Nacional de Tecnologia Educacional (Prolnfo) do Ministério da Educação, que distribuiu tablets para professores do Ensino Médio da rede pública, e o Programa Banda Larga nas Escolas (PBLE) do Ministério das Comunicações, que visava garantir o provimento da Internet em escolas. Uma possível crítica às políticas públicas mencionadas se relaciona ao enfoque atribuído ao hardware e à infraestrutura, que não busca integração com aspectos pedagógicos de aplicação da tecnologia. Rosa e Azenha (2015, p. 111) comentam que, no que tange ao programa de distribuição de tablets, por exemplo, “[n]ão foram desenvolvidas ações específicas com foco em conteúdo e treinamento de professores - ações a cargo dos governos locais".

Dessa forma, o conceito de aprendizagem móvel que muitas vezes é aplicado em instituições educacionais é meramente instrumental, isto é, centrado no dispositivo e sua natureza portátil, não na mudança dos processos de ensino-aprendizagem e na emancipação do usuário. Tal concepção é antiquada e remonta às primeiras definições do mobile learning, que basicamente relacionavam a aprendizagem com o uso de dispositivos móveis. Apesar de as definições sobre a aprendizagem móvel variarem dependendo da época e dos autores que

\footnotetext{
2 https://en.unesco.org/events/mobile-learning-week-2019

3 https://www.inderscience.com/jhome.php?jcode $=$ ijmlo

4 https://www.online-journals.org/index.php/i-jim
} 
trabalham com o conceito, há cada vez mais convergência entre os pesquisadores de que mobile learning não pode ser reduzido à junção entre o móvel e a aprendizagem, focalizando unicamente a portabilidade dos dispositivos, em uma visão tecnocêntrica (TRAXLER, 2009; HOCKLY, 2012; PEGRUM, 2014; SHARPLE, 2009).

Outro conceito de aprendizagem móvel que abrange uma visão somente parcial das potencialidades dessa abordagem é a utilização de dispositivos móveis como facilitadores do acesso a ambientes e materiais de educação a distância (EaD), ou seja, como um e-learning portátil. Traxler (2009) traz à baila a crítica de que, embora a aprendizagem móvel compreenda a noção de "e-learning móvel", esta também se concebe como uma reação a esse e-learning convencional e às suas inadequações e limitações. Saccol et al. (2011) complementam que é equivocado afirmar que o $m$-learning seja mera extensão do e-learning, uma vez que os dispositivos móveis podem ser usados também como suporte para maximizar experiências de aprendizagem presenciais, dentre outras formas de aprendizagem. 0 quadro 1 distingue, com base em Saccol et al. (2011), algumas práticas de educação formal que têm sido relacionadas ao conceito de mobile learning.

- E-learning portátil: Possibilidade de acessar um curso de EaD por meio de dispositivos móveis. Um exemplo é o $M y M L E$, um programa para computador que permite criar objetos de aprendizagem (OA) para celulares. ${ }^{5}$

- Aprendizagem em sala de aula apoiada por tecnologias móveis e sem fio: Iniciativa que envolve uma mobilidade restrita no ambiente educacional. Por exemplo, com alunos utilizando notebooks e redes sem fio em diferentes salas de aula ou dentro de determinado Campus ou instalação empresarial.

- Capacitação e treinamento móvel: Possibilidade de uso do m-learning na formação de trabalhadores móveis em campo.

- Inclusão e diversidade: Promoção do acesso à educação a grupos sociais menos favorecidos ou que se encontram em localidades isoladas, como comunidades rurais, assim como grupos com alguma necessidade especial (por exemplo, alunos com dislexia).

Quadro 1. Práticas educacionais de m-learning. Fonte: Adaptado de Saccol et al. (2011).

\footnotetext{
${ }^{5}$ http://mle.sourceforge.net/
} 
O conceito de mobile learning não pode, portanto, ser resumido à mobilidade dos aparelhos ou mesmo à mobilidade físicas dos aprendizes, pois se desdobra em diferentes tipos de mobilidades, que abrangem potencialidades e limitações educacionais específicas. Algumas dessas potencialidades serão discutidas a seguir.

3 Aprendizagem móvel: aplicativos como ferramentas cognitivas

A expansão e popularização das tecnologias móveis proporcionou um notável desenvolvimento de softwares para dispositivos móveis: os aplicativos. 0 Appfigures ${ }^{6}$, uma plataforma de relatórios para desenvolvedores de aplicativos, informa que foram disponibilizados mais de 2 milhões de aplicativos novos nas lojas Google Play e IOS no ano de 2017, conforme demonstra o gráfico 6 . É digno de nota que o Brasil, além de ávido consumidor de aplicativos, ocupou, segundo a AppFigures, $05^{\circ}$ lugar no ranking de países desenvolvedores de aplicativos para plataformas móveis no ano de 2017.

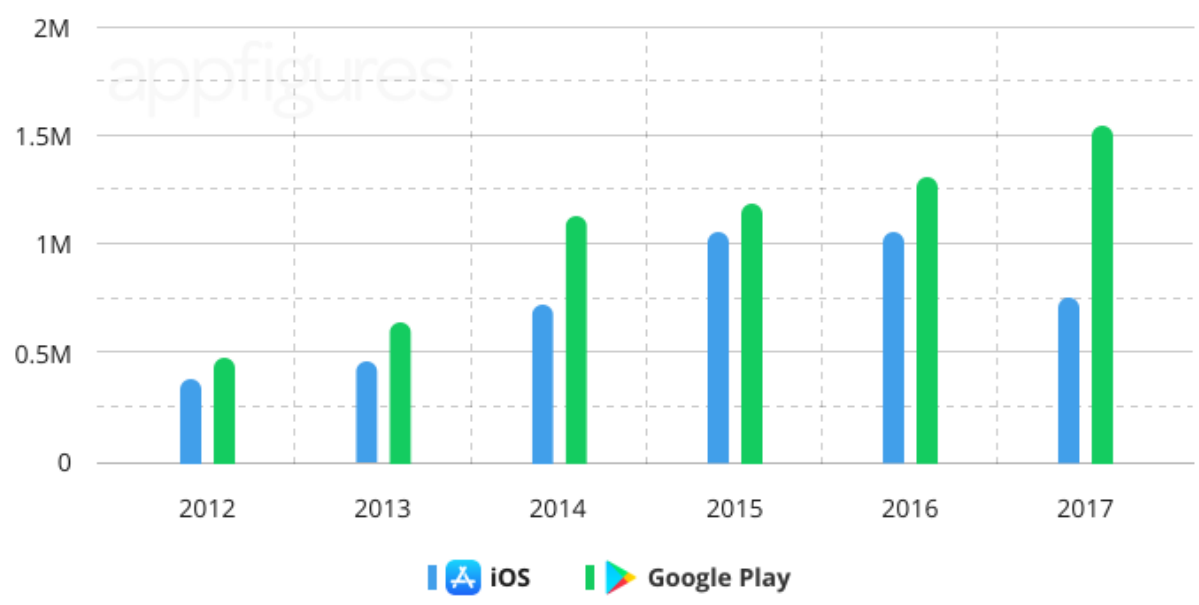

Gráfico 6. Lançamento de novos apps por ano. Fonte: Site da AppFigures.

Na seara dos aplicativos, encontram-se os softwares voltados para a educação, como é o caso do Kahoot. Há, ainda, aqueles apps que não foram produzidos para este contexto,

\section{${ }^{6}$ https://appfigures.com/about}


mas que possibilitam um enfoque educacional, como o Youtube. Em geral, esses aplicativos são gratuitos, ou possuem uma versão gratuita, com interface amigável e de fácil usabilidade.

Segundo Jonassen et al. (1998), há duas formas de interação com o conhecimento provenientes da aprendizagem a partir de tecnologias digitais. Os autores manifestam esse paralelo com base no valor semântico das preposições "de", expressando origem, e "com", expressando companhia, para delinear a ideia de se "aprender de" ou "aprender com" computadores. A primeira, que é também a forma mais tradicional, envolve a utilização de ferramentas digitais como tutores ou guias da aprendizagem, que controlam o processo e testam se o aprendiz é capaz de reproduzir o conhecimento esperado. A segunda confere aos aprendizes o caráter de designers da situação de aprendizagem, enquanto as ferramentas funcionam como mind tools - ferramentas mentais ou cognitivas - para interpretação e organização do conhecimento deles.

Em consonância com Jonassen et al. (1998), este estudo descreverá as potencialidades pedagógicas de dois aplicativos a partir desta perspectiva de ferramenta cognitiva, isto é, buscando ir além dos métodos de reprodução do conhecimento para propiciar experiências interpretativas e colaborativas que gerem uma aprendizagem significativa.

4 As (novas) possibilidades pedagógicas do Kahoot!

Kahoot! é uma plataforma de criação de jogos com perguntas de múltipla escolha lançada em 2013, mas que recentemente acrescentou novas possibilidades pedagógicas. A plataforma ascendeu à popularidade no meio educacional, principalmente, por possibilitar o desenvolvimento de envolventes questionários no formato quiz, capaz de mobilizar a turma em um verdadeiro game show. A maioria das ferramentas dispostas em Kahoot! é gratuita, apesar de haver uma versão pro e premium que expandem as possibilidades pedagógicas. 0 jogo pode ser acessado por computador ou por aplicativo.

O professor pode criar um novo quiz ou pesquisar quizzes que foram desenvolvidos por outros professores, editá-lo e compartilhá-lo com suas turmas. 0 jogo pode também ser adaptado para o formato de questão do tipo verdadeiro ou falso, conforme exposto na figura 
1, o que permite a criação de um quiz com estes dois modelos de questão na versão gratuita e com ainda outros modelos na versão paga.

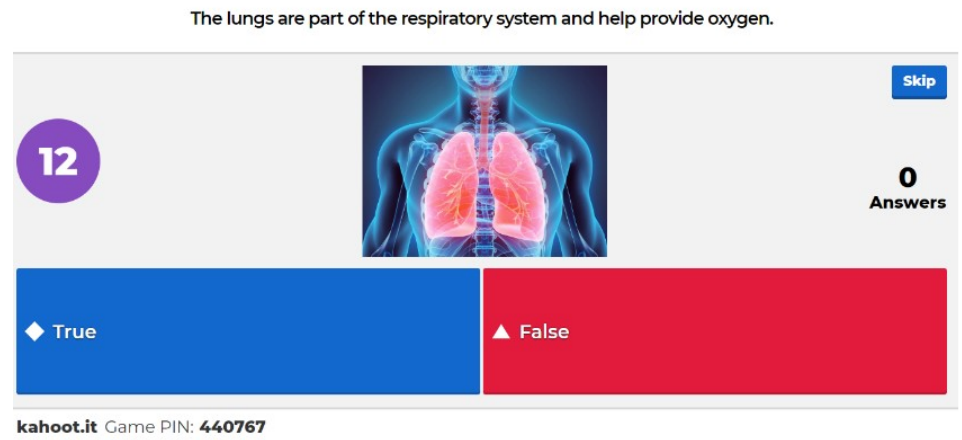

Figura 1. Quiz da disciplina de biologia em formato Verdadeiro ou Falso Fonte: Kahoot.

Nos quizzes, podem ser inseridos imagens ou vídeos e também pode ser estipulado um tempo para a realização de cada questão de até 240 segundos. A figura 1 traz um exemplo de um quiz da disciplina de história desenvolvido no Kahoot! que associa o conteúdo com imagens. Destaca-se que é possível realizar compreensão de textos também nesta plataforma, bastando este ser transportado para formato de imagem e de um tamanho que garanta a leitura. Na versão pro, é disponibilizado a inserção de slides entre as questões, 0 que propicia a realização de tarefas mais complexas, como é o caso da interpretação de textos ou problemas matemáticos mais longos, por exemplo.

\section{As imagens referem-se a que acontecimento?}

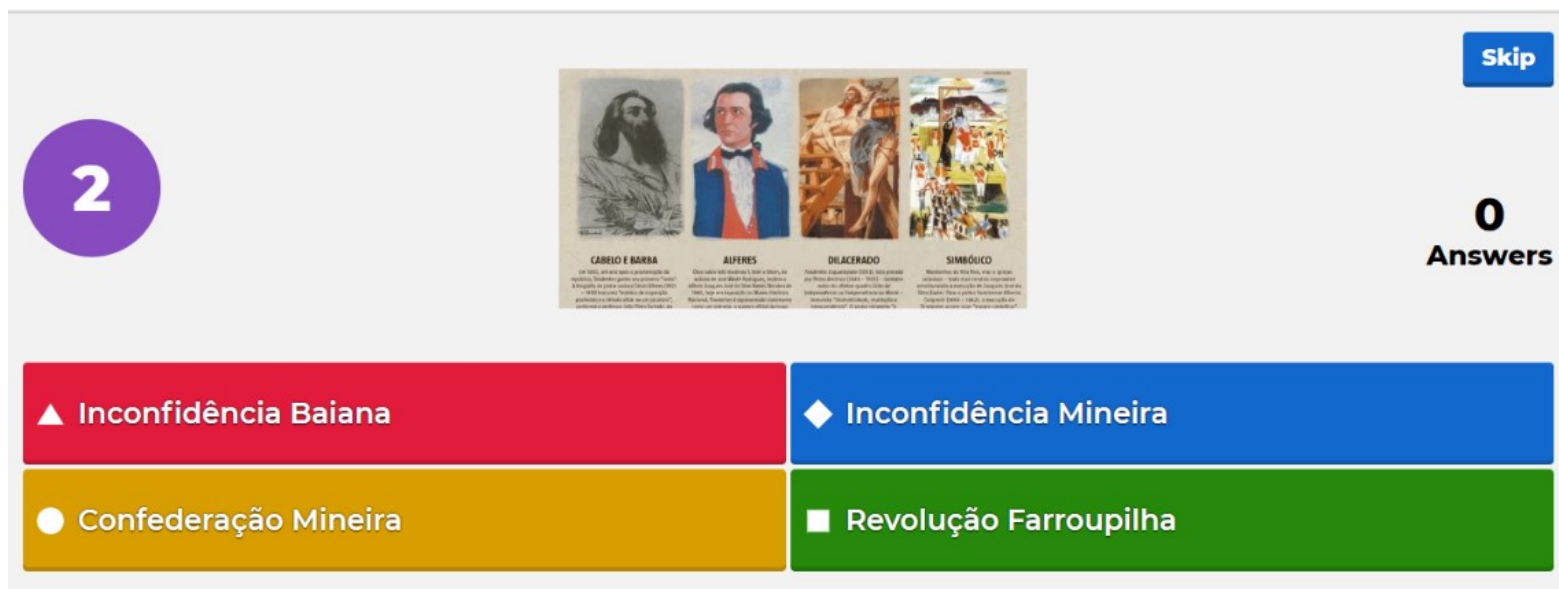

Figura 2. Quiz da disciplina de história que associa texto e imagem.

Fonte: Kahoot. 
Além das questões de múltipla escolha e verdadeiro ou falso, é possível desenvolver levantamentos e pesquisas com o Kahoot! na versão gratuita. A versão paga inclui também questões de resposta aberta e um jogo denominado puzzle. Este último não trata de responder a uma questão, mas colocar ideias em ordem, através do mecanismo de arrasta e solta. A figura 3 demonstra uma tarefa de ordenar frases em inglês, enquanto a figura 4 reproduz a tela do aluno. Neste jogo, é possível também ordenar palavras, equações, dentre outras atividades. Apesar de não ser possível criar questões de pergunta aberta e puzzles na versão gratuita, permite-se buscar quizzes desenvolvidos por outros professores que utilizem essas questões e utilizá-los com as turmas sem passar pela fase de edição.

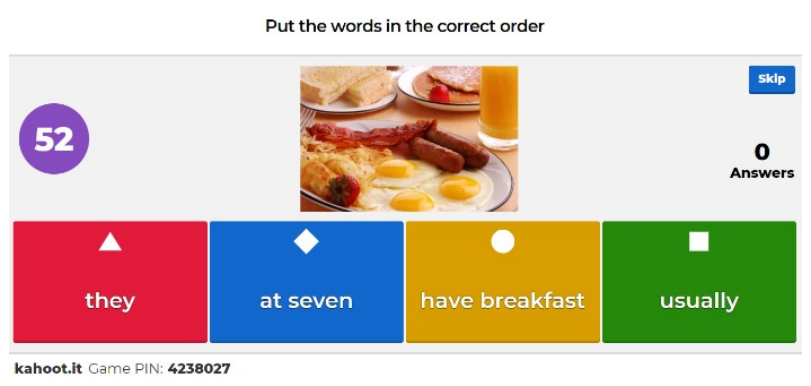

Figura 3. Puzzle da disciplina de inglês. Fonte: Kahoot.

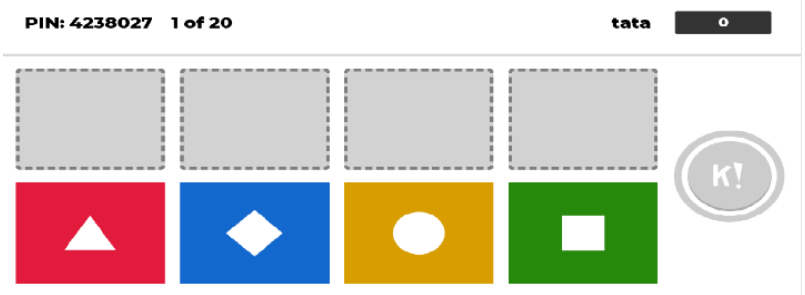

Figura 4. Tela do aluno do jogo puzzle. Fonte: Kahoot.

Um fator muito pertinente do Kahoot! é que ele permite que a tarefa seja realizada com toda a turma em tempo real na aula presencial ou a distância, sendo esta última realizada com o suporte de plataformas de conferência como Skype e Google Hangout, que também são gratuitas e permitem compartilhar a tela em que as questões serão exibidas. Outra forma de utilização a distância é através da ferramenta Challenge, que libera ao aluno um prazo para execução da tarefa, podendo esta ser acessada no horário e local de sua preferência, pelo 
computador ou pelo aplicativo. O Challenge pode ser inserido no planejamento pedagógico como um dever de casa para reforçar um conteúdo ou como uma tarefa da metodologia da Sala de Aula Invertida (SAI). Ademais, o Challenge pode ser utilizado até mesmo durante a aula presencial de maneira que cada aluno realize as questões no seu próprio tempo. 0 Challenge na sala de aula prioriza a atenção e precisão nas respostas, diminuindo as adivinhações. A figura 5 mostra o compartilhamento de um Challenge em que se evidencia a opção de atribuir ou não tempo específico para a execução do quiz na opção Question Timer.

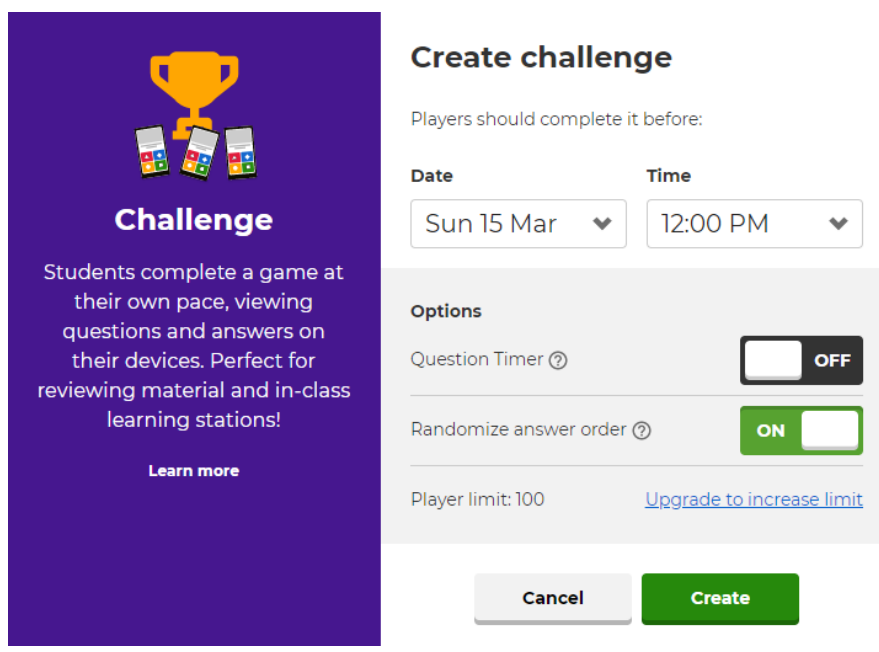

Figura 5: Challenge. Fonte: Kahoot.

Kahoot! disponibiliza ainda uma potente ferramenta para a avaliação formativa. A cada realização de um jogo, a plataforma gera automaticamente um relatório bastante completo do resultado geral da turma, de cada aluno e de cada questão do questionário. 0 relatório pode ser exportado do site em formato de planilha do Excel. Analisar o relatório pode indicar qual parte do conteúdo e quais alunos precisam de reforço.

Na versão tradicional de uso do Kahoot!, isto é, com as tarefas sendo desenhadas pelos professores, o jogo já conduz a uma aprendizagem mais significativa, pois fomenta 0 engajamento e a diversão na aprendizagem. No entanto, como a plataforma apresenta mecanismos bem simples para o desenvolvimento de atividades, uma possibilidade para incentivar o protagonismo do aluno é convidá-los a produzir quizzes na plataforma Kahoot! Para tal, após uma capacitação de como utilizar a plataforma, os alunos só precisam se registrar no site para criar quizzes de seus computadores ou telefones celulares. Esta 
atividade pode ser desenvolvida em qualquer etapa do planejamento e com qualquer conteúdo que se deseje reforçar, enquanto proposta individual ou coletiva. O projeto pode ser focado na criação de um kahoot ou envolver uma apresentação temática que tenha como culminância a realização do quiz. Os alunos podem produzir os quizzes na aula presencial ou a distância, receber o feedback do professor sobre o jogo e, então, lançar o jogo o vivo na aula ou através de Challenge.

Em geral, muitas são as possibilidades pedagógicas que advém dessa proposta de convidar os alunos a ocupar o papel de designers ou codesigners de kahoots. Assim, a ferramenta funciona como mind tool - ferramenta cognitiva - envolvendo o estudo, interpretação, seleção e organização do conteúdo.

5 Das vídeoaulas às playlists coletivas no Youtube

O Youtube é, atualmente, a plataforma mais popular de compartilhamento de vídeos na Web. É uma plataforma gratuita, apesar de possuir uma versão premium que exclui os anúncios, e pode ser acessada pelo computador ou por aplicativo. Dentre os milhões de vídeos disponibilizados na plataforma, muitos deles possuem conteúdo educacional, como é o caso dos vídeos sobre experimentos científicos, vídeos de slides e, claro, as famosas vídeoaulas. Em 2013, a Google lançou no Brasil o YouTube/Edu, um canal dedicado a vídeos educacionais desenvolvido em parceria com a Fundação Lemann. O Youtube/Edu seleciona e agrega vídeos de educação feitos por professores brasileiros para todas as disciplinas do Ensino Médio, com enfoque particular nos conteúdos exigidos pelo Exame Nacional do Ensino Médio (Enem). As vídeoaulas publicadas nesta plataforma passam pela curadoria de uma comissão de professores, que avaliam a veracidade das informações e a qualidade das aulas. A figura 6 dispõe imagem da plataforma Youtube/Edu. 


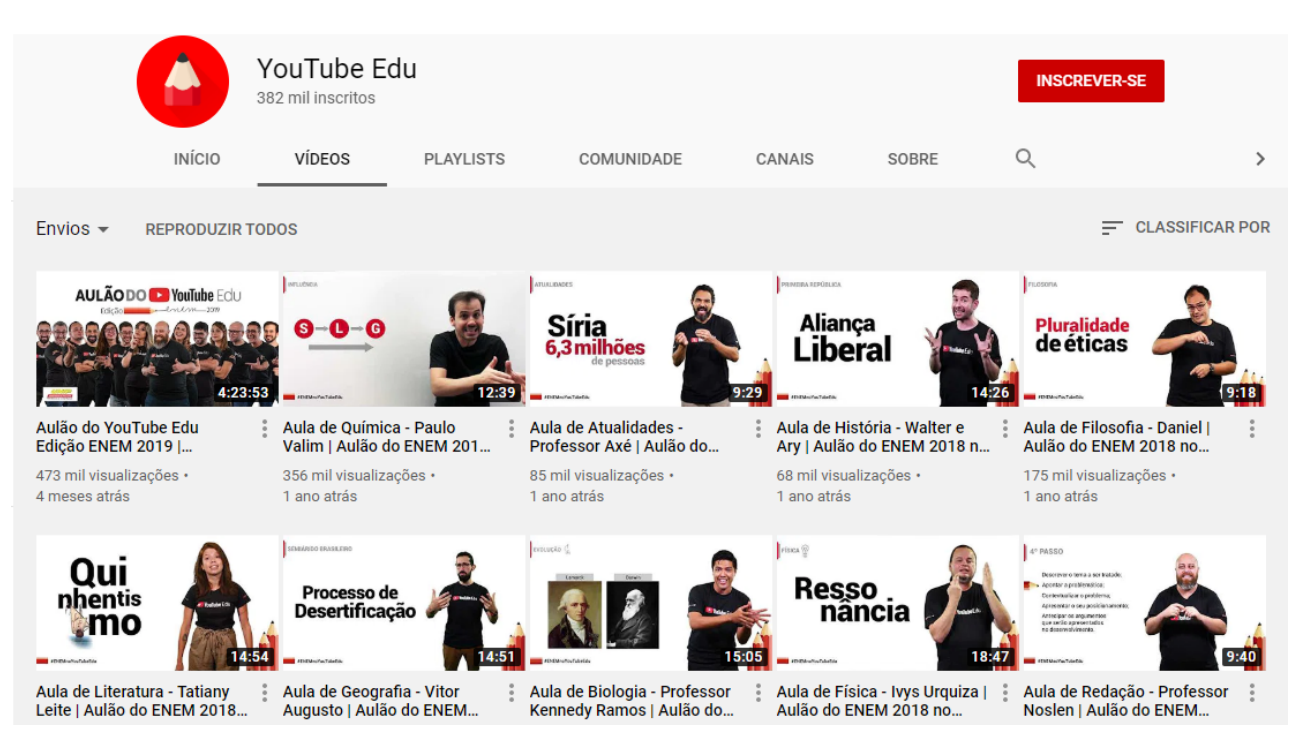

Figura 6. Plataforma Youtube/Edu.

Fonte: Youtube.

Assim como o Kahoot!, é possível utilizar as vídeoaulas do Youtube na sala de aula ou fora dela, como dever de casa após a aula ou como dever que antecede a aula na SAI. Acessar um conteúdo de qualidade em vídeo pode fazer toda a diferença para a aprendizagem do aluno, pois permite que ele acesse o conteúdo quantas vezes for preciso, efetue pausas, faça anotações, volte ou adiante o vídeo, estudando de acordo com seu ritmo de aprendizagem. No que tange à SAI, uma proposta proveitosa é articular uma videoaula do Youtube a um quiz do Kahoot!. Assim, o aluno se prepara melhor para a aula e o professor recebe o feedback sobre as questões que deve retomar.

As atividades citadas são de grande valia, pois possibilitam uma personalização da aprendizagem. No entanto, trata-se essencialmente de um material que foi selecionado pelo professor e recebido pelo aluno. Neste contexto, o professor pode incentivar o aluno a procurar outras fontes e comparar com a informação que aprendeu no vídeo, construindo, assim, um conhecimento mais significativo. Um aluno altamente motivado poderá fazê-lo, enquanto um outro aluno que não esteja tão interessado naquele determinado assunto poderá somente assistir ao vídeo.

Uma maneira de utilizar o Youtube como uma ferramenta cognitiva consiste em criar uma playlist coletiva na própria plataforma. Dessa forma, os alunos realizariam a curadoria dos vídeos, o que demanda uma análise mais profunda do conteúdo e da forma como este é 
apresentado. As playlists podem ser confeccionadas em grupos ou entre toda a turma, como é o caso da playlist exibida na figura 7.

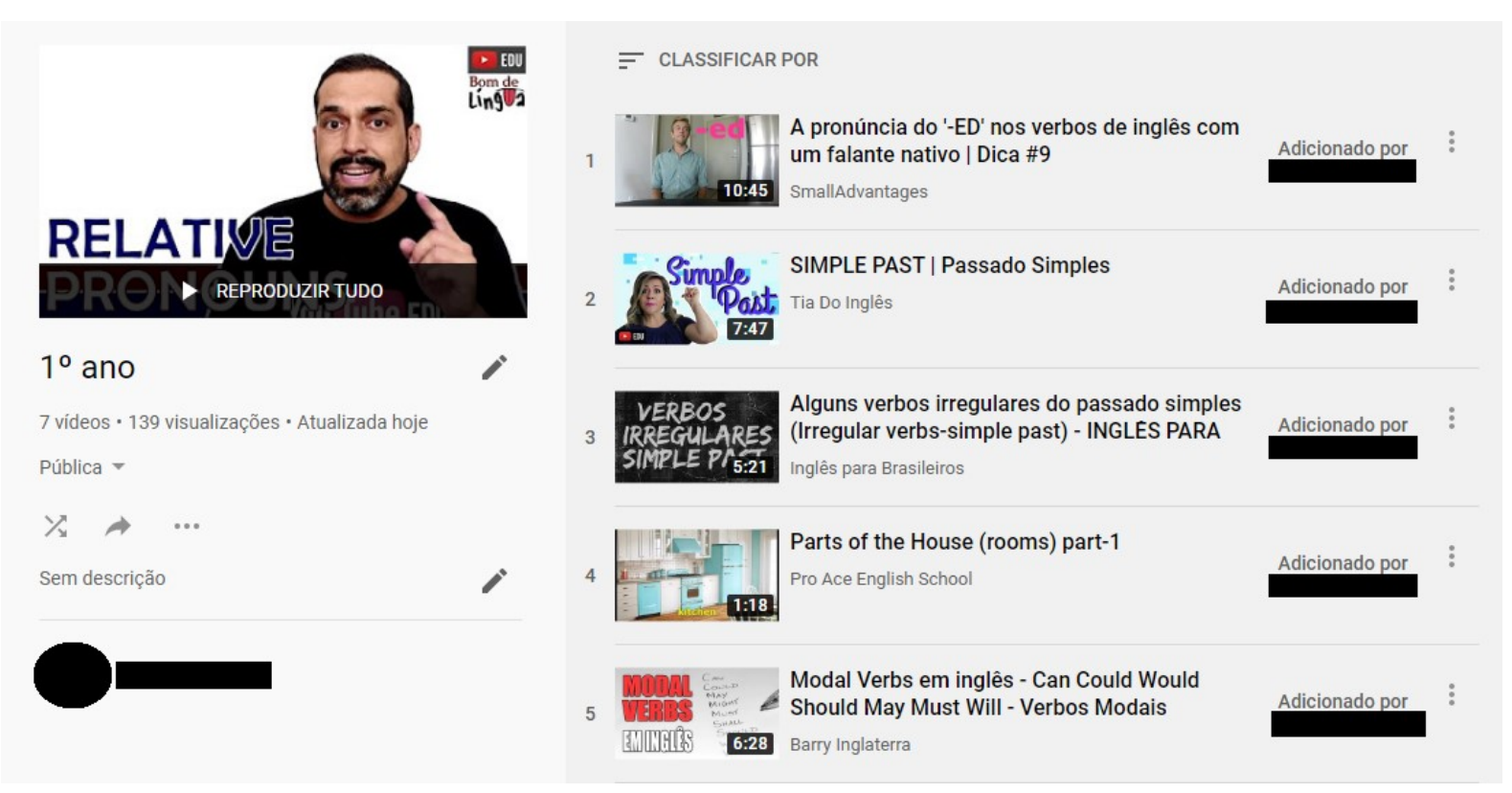

Figura 7. Playlist no Youtube. Fonte: Youtube.

Para garantir que o conteúdo esteja de acordo com o currículo, o professor pode elaborar uma lista de elementos essenciais que devem estar presentes nos vídeos. Assim, enquanto o aluno se torna curador, o professor se posiciona como orientador/facilitador do processo.

6 Considerações finais

A expansão das tecnologias móveis, apesar de ser marcada por desigualdades que geram um fosso digital, tem se mostrado veloz e contínua. No Brasil, o número de linhas de telefonia móvel já superou o número de habitantes e o número de assinaturas de banda larga móvel já chega a 67.5\% da população (ITU, 2017; 2018). Além disso, os dados parecem corroborar a ideia sobre o surgimento de uma cultura móvel juvenil, que utiliza as redes como lócus de (re) construção de identidades (ARTOPOULOS, 2011). 
Nas escolas, os telefones celulares se tornaram objetos tão comuns quanto canetas e cadernos. As potencialidades desses dispositivos, que são, de fato, microcomputadores, já ocupa o lugar de tema principal de teses, livros, congressos e periódicos de âmbito educacional. A proibição de uso dos telefones celulares nas escolas está sendo burlada por professores que se empenham para planejar aulas e produzir materiais que integrem o uso dos telefones celulares dos alunos no currículo de suas disciplinas. Tal integração pode, todavia, focalizar em demasia os dispositivos em uma visão tecnocêntrica, o que deve ser evitado, tendo em vista as possibilidades da aprendizagem móvel de maximizar experiências de aprendizagem presenciais e a distância (SACCOL et al., 2011; TRAXLER, 2009).

O uso das tecnologias móveis na educação pode promover mudança dos processos de ensino, como a personalização da aprendizagem e a emancipação do aluno. Esta última é alcançada, sobretudo, quando a proposta didática inclui uma perspectiva da tecnologia enquanto ferramenta cognitiva (JONASSEN et al., 1998). Neste caso, a tecnologia é utilizada pelo aluno como ferramenta para se construir determinado conhecimento através da organização e interpretação de informações. Assim obtém-se o "aprender com computadores", que, para Jonassen et al. (1998), é diferente do "aprender de computadores".

Neste artigo, propostas de implementação da aprendizagem móvel na educação básica foram apresentadas com base nos aplicativos Kahoot! e Youtube. Demonstrou-se algumas potencialidades pedagógicas do Kahoot!, destacando-se o projeto de criação coletiva de quizzes como uma possibilidade para incluir o aluno como designer da aprendizagem. Da mesma forma, as vídeoaulas do Youtube ganham relevo, principalmente, para atividades não presenciais, mas a atividade de criação coletiva de playlist se sobrepõe por posicionar o aluno como curador da aprendizagem.

Esses simples exemplos de integração da aprendizagem móvel na educação básica propiciam que os alunos não só "aprendam de aplicativos", mas também "aprendam com aplicativos". Como designer e curador do próprio processo de aprendizagem, o aluno acaba por aprender a aprender. 
Referências

ARTOPOULOS, A. Notas sobre a cultura juvenil móvel na América Latina. In: BEIGUELMAN, G.; FERLA, J. (orgs.) Nomadismos tecnológicos. São Paulo: Editora Senac São Paulo, p. 35-54, 2011.

CASTELLS, M.; ARDEVOL, M. F.; QIU, J. L.; SEY, A.. The mobile communication society. A cross-cultural analysis of available evidence on the social uses of wireless communication technology. A research report prepared for the International Workshop on Wireless Communication Policies and Prospects: A Global Perspective, held at the Annenberg School for Communication, University of Southern California, Los Angeles, October 8th and $9^{\text {th }}$, 2004.

Disponivel

em:

http://citeseerx.ist.psu.edu/viewdoc/download?doi=10.1.1.109.38728rep=repı\&type=pdf

Acesso em: ol de ago de 2019.

EVANGELISTA, R. M. F. As políticas de tecnologias móveis na educação: técnicas de governamento dos outros e de si. Dissertação de mestrado. Programa de Pós-Graduação em Educação - Mestrado da Universidade Federal de Ouro Preto, 2017. Disponível em: https://www.repositorio.ufop.br/bitstream/123456789/9676/1/DISSERTACAO Pol\%C3\%AD ticasTecnologiasM\%C3\%B3veis.pdf Acesso em: 20 de nov de 2019.

HOCKLEY, N. Mobile learning. ELT Journal. Oxford University Press, 2012.

INTERNATIONAL TELECOMMUNICATION UNION (ITU). Measuring the Information Society Report 2018 - Volume 1. Place des Nations CH-1211 Geneva Switzerland, 2018. Disponível em: $\quad$ https://www.itu.int/en/ITU-D/Statistics/Documents/publications/misr2018/MISR2018-Vol-1-E.pdf Acesso em: o1 de ago de 2019.

Measuring the Information Society Report 2017- Volume 2:

ICT country profiles. Place des Nations $\mathrm{CH}-1211$ Geneva Switzerland, 2017. Disponível em: https://www.itu.int/en/ITU-

D/Statistics/Documents/publications/misr2017/MISR2017_Volume2.pdf Acesso em: ol de ago de 2019.

Measuring the Information Society Report 2018 - Volume 2: ICT country profiles. Place des Nations $\mathrm{CH}-1211$ Geneva Switzerland, 2018. Disponível em: https://www.itu.int/en/ITU-D/Statistics/Documents/publications/misr2018/MISR-2018Vol-2-E.pdf Acesso em: 01 de ago de 2019. 
JONASSEN, D. H.; CARR, C.; YUEH, H-P. Computers as Mindtools for Engaging Learners in Critical Thinking. TechTrends. v43 n2 p24-32 Mar, 1998. Disponível em: http://citeseerx.ist.psu.edu/viewdoc/download?doi=10.1.1.485.75838rep=rep1\&type =pdf Acesso em: 11 de mar de 2020.

MOURA, A. M.C.. Apropriação do telemóvel como ferramenta de mediação em Mobile Learning. Estudos de caso em contexto educativo. Tese de Doutoramento em ciências da Educação, na especialidade de tecnologia educativa, da Universidade do Minho. Braga, 2010.

ORGANIZAÇÃO PARA A COOPERAÇÃO E DESENVOLVIMENTO ECONÔMICO (OCDE). Understanding the digital divide. OECD Publication, France: 2001. Disponível em: http://www.oecd.org/internet/ieconomy/1888451.pdf Acesso em: ol de ago de 2018.

PEGRUM, M. Mobile learning: languages, literacies and cultures. [Kindle edition] The Palgrave Macmillan. London, 2014.

PRENKSY, M. Digital natives, digital immigrants: do they really think differently? On the Horizon. MCB University Press, Vol. 9 No. 5, October 2001. Disponível em: http://www.marcprensky.com/writing/Prensky\%20\%20Digital\%20Natives,\%20Digital\%20lmmigrants\%20-\%20Partı.pdf Acesso em 13 de ago de 2019.

ROSA, F.; AZENHA, G. S. Aprendizagem móvel no Brasil: gestão e implementação das políticas atuais $e$ perspectivas futuras. Zinnerama: São Paulo, 2015. Disponível em: http://www.aprendizagem-movel.net.br/ Acesso em 27 de nov de 2019.

SACCOL, A.; SCHLEMMER, E.; BARBOSA, J.. M-learning e U-learning: novas perspectivas da aprendizagem móvel e ubíqua. São Paulo: Pearson Education do Brasil, 2011.

SHARPLES, M.; ARNEDILLO-SÁNCHES, I.; MILRAD, M; VAVOULA, G.. Mobile learning: small devices, big issues. In: Balacheff, N., at al.(eds) Technology enhanced learning: Principles and products. Berlim: Springer, 2009.

TAPSCOTT, D. Geração digital: a crescente e irreversível ascensão da geração net. São Paulo: Makron books do Brasil, 1999. 
TRAXLER, J.. Learning in a mobile age. International Journal of Mobile and Blended Learning. $1 / 1: 1-12,2009$.

VEEN, W., \& VRAKKING, B. Homo zappiens: educando na era digital. Porto Alegre: Artmed, 2009.

Data de submissão: 02/04/2020. Data de aprovação: 05/05/2020. 